\title{
ESTIMATIVA DE PERDA DE SOLO NO OESTE DA BAHIA (BRASIL) A PARTIR DA ALTERAÇÃO DO USO E COBERTURA DA TERRA
}

\author{
André Barbosa Ribeiro Ferreira \\ Programa de Pós-Graduação em Geografia - Universidade Estadual Paulista - UNESP, Rio Claro \\ andreribeirogeo@gmail.com
}

Gabriel Pereira
Departamento de Geociências, Programa de Pós-Graduação em Geografia Universidade Federal de São João
del-Rei, MG
pereira@ufsj.edu.br

Bráulio Magalhães Fonseca Instituto de Geociências, Departamento de Cartografia e Pós-Graduação em Modelagem Ambiental Universidade Federal de Minas Gerais brauliomagalhaes@cart.igc.ufmg.br

Julio Cesar Costa

Programa de Pós-Graduação em Geografia - Universidade Federal de São João del-Rei, MG julioczcta@gmail.com

Francielle da Silva Cardozo

Programa de Pós-Graduação em Geografia - Universidade Federal de São João del-Rei, MG franciellecardozo@ufsj.edu.br

\section{RESUMO}

A utilização exacerbada dos recursos naturais gera prejuízos socioambientais e econômicos. O uso intensivo do solo e a conversão do Uso e Cobertura da Terra (UCT) unidos representam um risco ainda maior, pois favorecem a intensificação dos processos erosivos. Diante disso, essa pesquisa teve como objetivo efetuar uma comparação do UCT para os anos de 1985 e 2015 e aplicar a Equação Universal de Perda de Solos (EUPS) para a região do extremo oeste baiano. Essa região no decorrer das últimas décadas vem passando por uma intensiva expansão dos cultivos agrícolas, alterando de maneira significativa o UCT a partir do desmatamento, propiciando e acelerando processos que até então ocorriam de maneira natural. A quantificação da perda de solo foi estabelecida para a região a partir da aplicação da EUPS e apontou que no ano de 1985 as perdas foram 29\% superiores a 2015. O resultado não indica que as áreas agrícolas oferecem maior proteção ao solo, e pode ser explicado pelo contexto histórico de abertura das fronteiras agrícolas, que teve seu auge a partir da década de 1960 e utilizava fortemente o fogo para este propósito, deixando o solo exposto por mais tempo e tornando-o mais susceptível às intempéries.

Palavras Chave: Geoprocessamento. EUPS. Erosão. Oeste baiano - BA.

\section{ESTIMATION OF LOSS OF SOIL IN THE WEST OF BAHIA (BRAZIL) FROM THE AMENDMENT OF THE USE AND COVERAGE OF THE EARTH}

\section{ABSTRACT}

The exacerbated use of any natural resources generates environmental, social and economic impacts. The intensive use of soil and the conversion of Land Use and Land Cover (LULC) together represents a greater risk, since they favor the intensification of erosion processes. Therefore, this research has as objective to make a comparison of the LULC for 1985 and 2015 years and to apply the Universal Soil Loss Equation (USLE) to the extreme west region of Bahia. Over the last decades, this region has undergone an intensive expansion of agricultural crops, significantly altering the LULC due to deforestation, propitiating and accelerating processes that until then occurred in a natural way. The quantification of soil loss was established for the region from the application of the
\end{abstract}


USLE, and pointed out that in 1985 the soil losses were $29 \%$ higher than in 2015 . The result does not indicate that the agricultural areas offer greater protection to the soil, and can be explained by the historical context of the opening of the agricultural frontiers, which had its peak since the 1960s and heavily used fire for this purpose, leaving the soil exposed for longer and making it more susceptible to weathering.

Keywords: Geoprocessing. USLE. Erosion. West baiano - BA.

\section{INTRODUÇÃO}

A região oeste do estado da Bahia tornou-se a principal fronteira agrícola do estado a partir de 1980 e conheceu uma expansão agropecuária sem precedentes. Em razão do acréscimo significativo das áreas ocupadas por grãos, cultivos perenes e agricultura irrigada, ocorreram diversas transformações na paisagem, principalmente em relação ao uso da terra. Essas transformações e a ocupação sem planejamento geraram uma grande quantidade de desequilíbrios ambientais locais e regionais, como alterações do regime hídrico, supressão excessiva da vegetação e aumento exacerbado da erosão dos solos (BATISTELLA et al., 2002).

Nesse sentido, os solos, além de outros recursos, merecem uma atenção especial, principalmente pela intensa exploração agrícola que ao longo dos anos esgota os seus nutrientes e gera ou intensifica processos como a erosão. Este fenômeno vem despertando interesse de muitos pesquisadores no que se refere às causas de suas origens, evolução e controle, em razão de atingir e inutilizar extensas áreas de terras (PEDRO; LORANDI, 2004).

Os estudos sobre a erosão dos solos começaram a ser efetuados por volta de 1917, quando Duley desenvolveu um conjunto de sete parcelas de erosão localizada no campus da Universidade do Missouri - EUA. Tais estudos, dentre outros, deram início ao desenvolvimento de tecnologias e análises de perda de solo (LAFLEN; FLANAGAN, 2013). No decorrer do tempo surgiram avanços e adaptações às técnicas, até que em 1946 uma comissão nacional se reuniu em Ohio com a finalidade de adaptar a equação até então utilizada. A fórmula resultante ficou conhecida como a equação de Musgrave (WISCHMEIER; SMITH, 1965), a primeira equação completa para predição da perda de solo por erosão, expressa em polegadas ao ano (PINHEIRO, 2012).

Posteriormente, algumas alterações foram feitas com intuito de adaptar a fórmula para cada cenário distinto. Devido à grande utilidade das equações de perda de solo, em 1954 foi criado um Centro de Dados visando o desenvolvimento de uma equação nacional. Dessa forma, em 1965 Wischmeier e Smith, usando as informações desse Centro de Dados, dentre outras conclusões, desenvolveram a Universal Soil Loss Equation (Equação Universal de Perda de Solos - EUPS) (PINHEIRO, 2012). Conforme Schultz (2012), esse método consiste em uma equação que estima a quantidade média de solo perdido em função do processo de erosão hídrica considerando seis fatores: clima, solo, relevo, uso e cobertura da terra, práticas conservacionistas e topografia. O cálculo da EUPS envolve fatores naturais e antrópicos expressos na Equação

\section{$A=R \cdot K \cdot$ LS.C.P}

(1) em que $\mathrm{A}$ representa a perda de solos; $\mathrm{R}$ a precipitação; $\mathrm{K}$ a erodibilidade do solo; LS a topografia; $C$ o uso e cobertura da terra e $\mathrm{P}$ as práticas conservacionistas.

Segundo Uddin et al. (2016), a EUPS é amplamente utilizada para estimar a perda de solo anual a partir da combinação de fatores geofísicos e cobertura da terra. Olivares et al. (2015) consideram que o modelo contempla a ação dos fatores precipitação, solo, topografia, cobertura da terra, práticas de conservação e proporciona informações rápidas e eficazes a respeito da perda (PATIL et al., 2014).

No Brasil, os trabalhos iniciais sobre a EUPS foram desenvolvidos por Bertoni e Lombardi Neto (2008) no estado de São Paulo, sendo posteriormente bases para diversos outros autores nas demais regiões.

Para este estudo a EUPS foi empregada no extremo Oeste baiano, região que no decorrer das últimas décadas sofreu perdas significativas da cobertura vegetal original em detrimento da expansão

$\begin{array}{llllll}\text { Caminhos de Geografia } & \text { Uberlândia } & \text { v. 20, n. } 72 & \text { Dez/2019 } & \text { p. 560-573 } & \text { Página } 561\end{array}$


agrícola. Desse modo a pesquisa tem o objetivo de analisar as relações entre as mudanças no uso e cobertura da terra e a perda de solos por erosão a partir de um comparativo temporal de trinta anos (1985/2015).

\section{ÁREA DE ESTUDO}

A área de estudo (Figura 1) está inserida na Região Oeste do estado da Bahia, entre as coordenadas $46^{\circ} 36^{\prime} 73^{\prime \prime} / 44^{\circ} 04^{\prime} 15^{\prime \prime} \mathrm{W}$ e $10^{\circ} 7^{\prime} 05^{\prime \prime} / 15^{\circ} 16^{\prime} 10^{\prime \prime} \mathrm{S}$. Com aproximadamente $88.680 \mathrm{~km}^{2}$ a área abrange 12 dos 24 municípios que compõem a Mesorregião Extremo Oeste Baiano e as bacias do Rio Grande, Rio Corrente e Carinhanha, afluentes do Rio São Francisco.

Figura 1 - Mapa de localização da área de estudo.

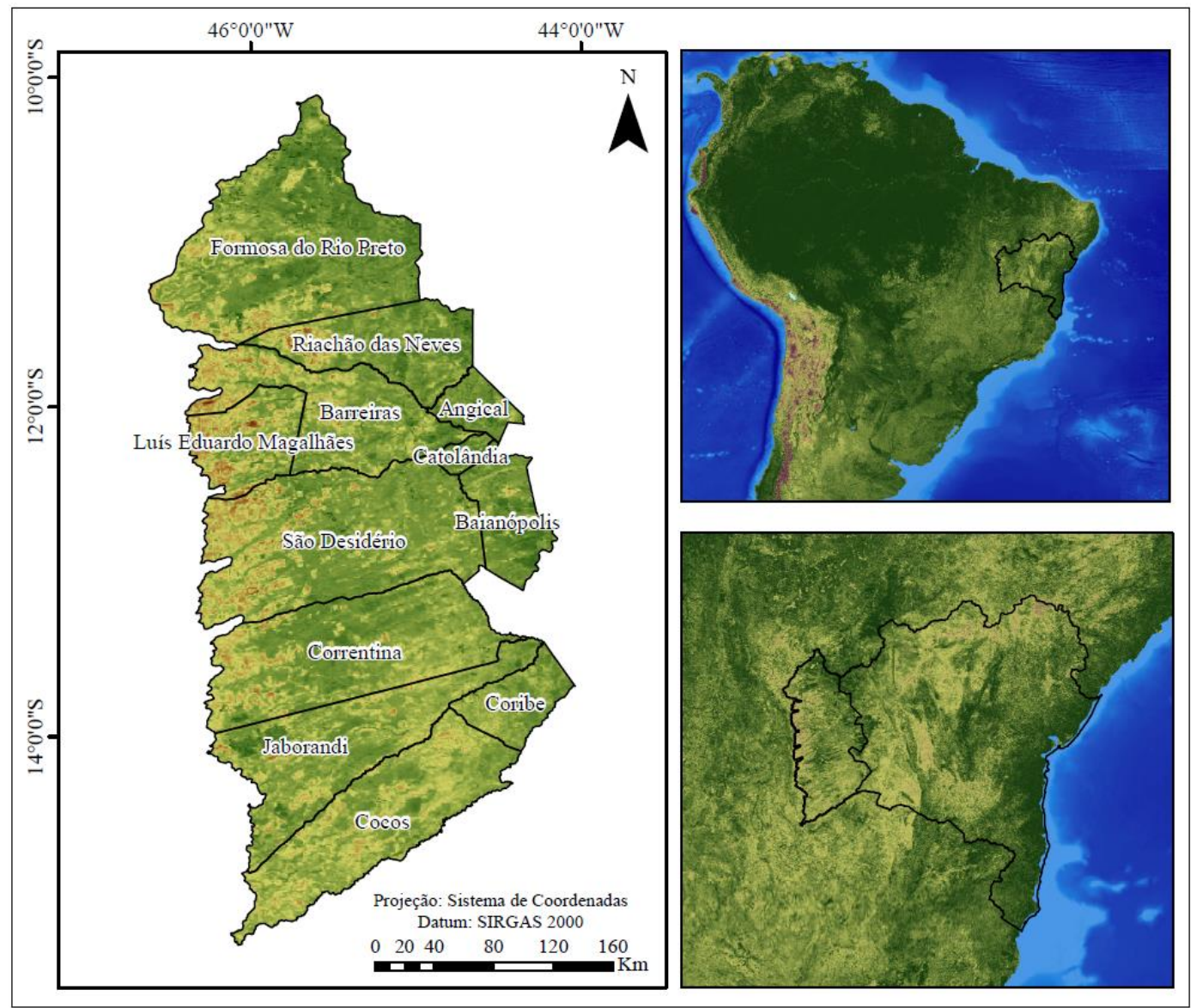

Fonte: Elaborado pelo autor. 2018.

O clima regional típico é semiárido, com variações de úmido a sub-úmido, seco a sub-úmido, classificado segundo Köppen como Aw (Tropical de Savanas), com duas estações bem definidas, apresentando clima quente e úmido entre os meses de outubro a abril e clima frio e seco de maio a setembro. As temperaturas médias na região variam entre $20^{\circ} \mathrm{C}$ e $26^{\circ} \mathrm{C}$, sendo mais amenas nas áreas mais elevadas (BATISTELLA et al., 2002).

$O$ relevo caracterizase como predominantemente aplainado, com altitudes que variam entre 350 e $1200 \mathrm{~m}$ e destaque ao Chapadão Central, uma plataforma aplainada formada sobre os arenitos Urucuia. A compartimentação geomorfológica é divida em cinco domínios principais, conforme Batistella et al. (2002), sendo eles:

\begin{tabular}{llllll}
\hline Caminhos de Geografia & Uberlândia & v. 20, n. 72 & Dez/2019 & p. 560-573 Página 562
\end{tabular}


I. Terraços aluviais: localizados próximos às margens do Rio São Francisco, são terrenos planos com variação altimétrica entre 350 e $400 \mathrm{~m}$.

II. Planalto Ocidental: predominante na região subdividido em Plataforma Aplainada, Baixadas e Encostas de Planaltos. As altitudes dessa compartimentação variam entre $450 \mathrm{~m}$ e $700 \mathrm{~m}$.

III. Planície Oriental: grande superfície aplainada, com algumas partes suavemente onduladas localizadas entre a frente oriental do Planalto Ocidental e o Rio São Francisco. As cotas altimétricas nessa área variam entre $400 \mathrm{~m}$ a $600 \mathrm{~m}$.

IV. Planícies e Pediplanos Setentrionais: área localizada próxima aos limites da Planície Oriental, corresponde a uma planície irregular intermontana e com setores pediplanados.

$V$. Serras e Incelbergs: maciços residuais elevados que variam em escarpados, ondulados e superfícies aplainadas com altitudes entre $500 \mathrm{~m}$ a $800 \mathrm{~m}$.

Os solos da região, segundo Batistella et al. (2002) são profundos, bem drenados, ácidos e deficientes em nutrientes, tendo a ocorrência diretamente relacionada ao relevo. No Planalto Ocidental ocorre a predominância dos Latossolos amarelos e vermelhos, além dos Neossolos Quartzarênicos, também encontrados nas áreas de planície. Nos vales e veredas são encontrados Gleissolos, enquanto nas Serras e Incelbergs destacam-se solos litólicos. Conforme o Ministério do Meio Ambiente (2017), podem ser encontrados, em menor quantidade, Cambissolos e Argissolos.

A ocupação inicial da região ocorreu a partir de expedições que desbravavam o sertão do São Francisco em busca da escravização indígena e, posteriormente, pelas sesmarias, que entre os séculos XVI e XVII deram origem aos primeiros povoados (QUEIROZ, 2012, p.19).

\section{METODOLOGIA}

A aplicação da EUPS para a região oeste do estado da Bahia fundamentou-se no método (script) criado por Fujaco (2017), como ferramenta de gestão remota a bacias hidrográficas agrícolas. A técnica, denominada pela autora (Op.Cit) como "USLE Paracatu Watershed", criada em linguagem Python, baseia-se na utilização do modelo que, adicionado à interface gráfica do Model Builder do Software ArcGis como extensão no ArcToolbox, possibilitou a inserção dos fatores que compõem a EUPS em formato vetorial e matricial (Figura 2).

Figura 2 - USLE Paracatu Watershed - ArcMap.

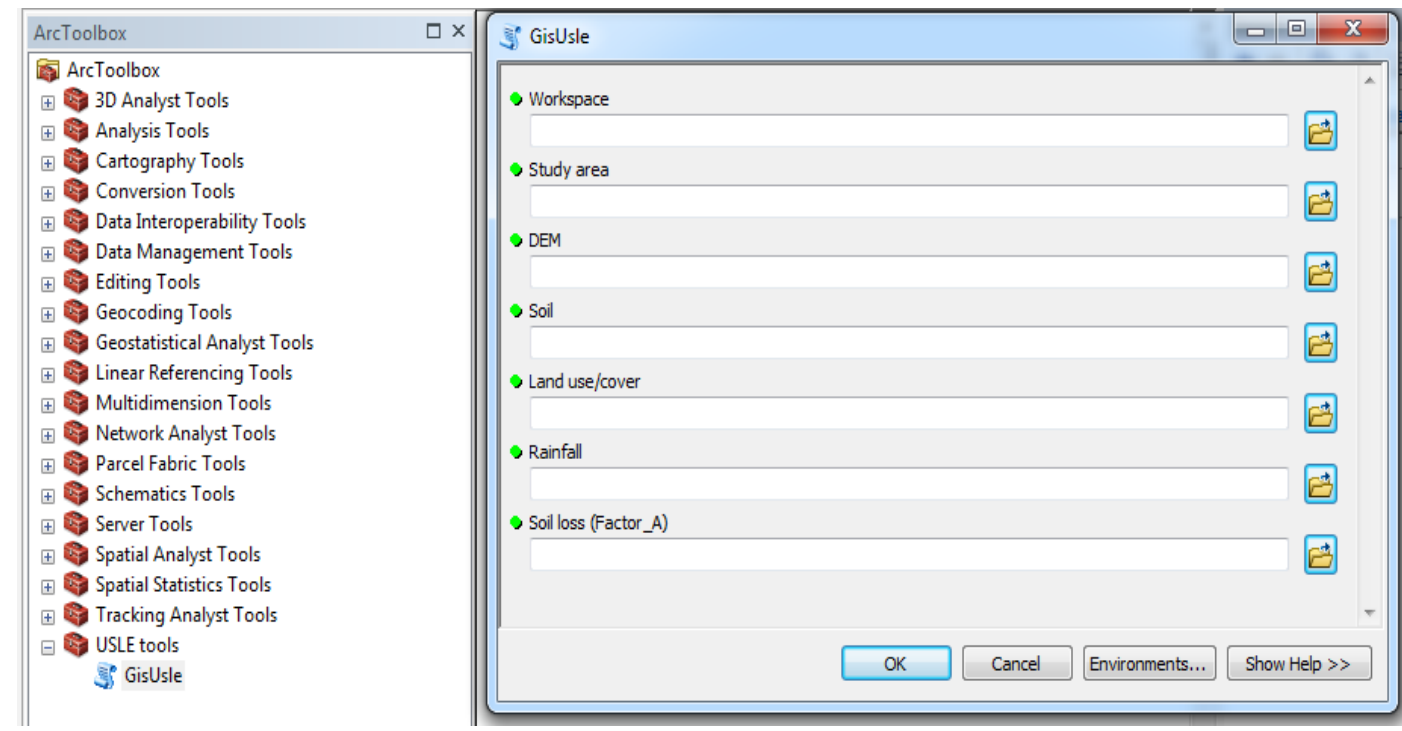

Fonte: Fujaco. Ano: 2017.

\begin{tabular}{llllll}
\hline Caminhos de Geografia & Uberlândia & v. 20, n. 72 & Dez/2019 & p. 560-573 Página 563
\end{tabular}


Segundo Fujaco et al. (2016), essa modelagem corresponde a um mecanismo de geoprocessamento onde cada uma das análises (fatores) gerou um arquivo final, sendo DEM (Fator LS) e Rainfall (Fator R) em formato TIFF, Study area (delimitação da área de estudo) e Soil Loss (Fator CP) em formato shapefile. Estes resultados foram inseridos nos respectivos campos (Figura 2) da extensão "USLE Paracatu Watershed" como bases de uma cartografia analítica e, posteriormente, processados e compilados de modo a resultar um único arquivo síntese (Fator A) com a estimativa de perda de solos. $\quad O$ procedimento metodológico para a obtenção das variáveis que compõe a EUPS é descrito separadamente abaixo:

\section{Fator $\mathbf{R}$}

O Fator $\mathrm{R}$ representa a erodibilidade da chuva e é adquirido a partir do cálculo de intensidade máxima de precipitação no intervalo de três horas. Para melhor acurácia das informações optou-se por não utilizar dados das estações meteorológicas da região, considerando que a mesma possui apenas três estações automáticas concentradas na região leste da área de estudo e uma na direção centro-leste, o que pode causar uma generalização dos resultados.

Segundo Hongfen et al. (2017), os medidores de chuva fornecem informações valiosas sobre a quantidade e a frequência das chuvas, todavia a distribuição espacial desigual e as incoerências espaciais limitam a estimativa pluviométrica. Neste contexto, a utilização de dados de precipitação a partir de um satélite fornece uma solução alternativa para este problema, pois proporcionam uma estimativa de precipitação espacialmente distribuída em grandes áreas.

Optou-se assim por utilizar dados do produto diário (3B42) do Tropical Rainfall Measuring Mission (TRMM), sensor que oferece dados pluviométricos a cada 3 horas e possui resolução espacial de $0.25^{\circ}$ entre as latitudes $50^{\circ} \mathrm{S}$ e $50^{\circ} \mathrm{N}$.

Foram selecionados dados de 03 de janeiro de 2000 a 22 de novembro de 2017, o que gerou 51.801 arquivos binários armazenados num método sequencial. Para que a leitura dos arquivos pudesse ser feita separadamente, dia a dia, fez-se necessário a conversão das linhas para uma sequência mensal/anual. Em seguida os dados foram exportados para o software Grid Analysis and Display System (GrADS) onde foram feitas as correções de ruídos e outras falhas.

A etapa seguinte consistiu em acoplar os dados dos dezessete anos e dez meses de modo a calcular a média mensal máxima e energia cinética dos eventos de precipitação na área de estudo durante esses anos. O cálculo foi efetuado no Software ENVI a partir da importação da imagem em formato TIFF e utilização da seguinte fórmula (Equação 2):

\section{$E c=11,87+8,73 \log 10 \mathrm{I}$}

Onde:

- EC - Energia Cinética MJ/ha-mm;

- I - Intensidade da chuva em $\mathrm{mm} / \mathrm{h}$.

O resultado gerado foi importado para o aplicativo ArcMap e convertido para pontos, contendo cada um deles informações como o EC e média de precipitação.

\section{Fator $\mathrm{K}$}

O Fator $\mathrm{K}$ corresponde a erodibilidade do solo, que expressa a resistência do solo à erosão hídrica, sendo dependente dos atributos mineralógicos, químicos, morfológicos entre outros (PRUSKI, 2010).

Os valores estabelecidos para a variável $\mathrm{K}$ (Tabela 1) foram baseados em referenciais bibliográficos, sobretudo na análise efetuada pela Codevasf (CHAVES, 1996), sobre o potencial de erosão no Vale do São Francisco, que atende a área de estudo, favorecendo a precisão dos valores condizentes com as características regionais.

\begin{tabular}{llllll}
\hline Caminhos de Geografia & Uberlândia & v. 20, n. 72 & Dez/2019 & p. 560-573 & Página 564
\end{tabular}


Tabela 1 - Fator K.

\begin{tabular}{cc}
\hline Solo & Fator K \\
\hline Latossolo Amarelo & 0,02 \\
Argissolo & 0,0029 \\
Cambissolo & 0,06 \\
Neossolo Quartzarênico & 0,078 \\
Gleissolo & 0,0081 \\
Neossolo Litólico & 0,035 \\
Latossolo Vermelho & 0,013 \\
\hline
\end{tabular}

Fonte: Codevasf. Ano: 1996.

\section{Fator L.S}

O fator LS possui estreita relação com a perda de solo, pois a declividade exerce influência direta na velocidade da enxurrada e, consequentemente, no transporte de materiais, e quanto maior o comprimento de rampa, maior é a velocidade da enxurrada e seu poder erosivo (CARVALHO JUNIOR et al., 2001).

Para a aquisição desses valores foram utilizadas imagens Aster Gdem adquiridas gratuitamente pelo United States Geological Survey (USGS). Para a cobertura da área de estudo foram necessárias 25 cenas do Digital Elevation Model (DEM) no formato TIFF. Essas imagens foram inseridas no software ENVI, onde foi efetuado o mosaico, e em seguida exportadas para o software Sistema de Processamento de Informações Georreferenciadas (SPRING) como um Modelo Numérico de Terreno (MNT) e recortadas de acordo com os limites da área de estudo.

No software SPRING, a partir de análise exploratória, obteve-se informações altimétricas máximas e mínimas, que proporcionaram o fatiamento e associação de classes temáticas para a confecção de mapas de declividade e hipsometria.

\section{Fator C e P}

O Fator $\mathrm{C}$ estabelece a perda de solo de acordo com a sua cobertura e manejo. Segundo Bertoni e Lombardi Neto (2008), as perdas de solo em uma área mantida descoberta podem ser estimadas pelos produtos $\mathrm{R}, \mathrm{K}, \mathrm{L}$ e S, no entanto, se a área for cultivada, tais perdas são reduzidas, levando-se em conta o estágio de crescimento e o período do ano (seco ou chuvoso).

A estimativa do valor de C é obtida a partir de parcelas experimentais e representa o grau de proteção média à erosão, sendo determinado de acordo com o tipo de cultivo e manejo da área, além do estado de desenvolvimento do plantio e suas influências na perda de solos. Considerando tais características, são utilizados valores de 0 e 1 para se classificar o fator $C$, de forma que os maiores valores representam menor proteção, enquanto os menores representam os cultivos/áreas que proporcionam maior proteção ao solo (PRUSKI, 2010).

Nesse estudo os fatores $\mathrm{C}$ e $\mathrm{P}$ foram analisados em conjunto, considerando-se que os fatores $\mathrm{P}$ e $\mathrm{C}$ só devem ser trabalhados de forma separada quando o objetivo do trabalho for definir configurações mais adequadas de plantio. Quando o foco for a perda de solos por erosão, essas variáveis interagem juntas, portanto, devem ser analisadas conjuntamente como CP (BORGES, 2009a), onde o Fator $\mathrm{P}$ é representado pelo número 1, não influenciando no resultado da análise ao multiplicar com as outras variáveis.

Para obter o fator CP, que corresponde ao UCT, utilizou-se como referência de mapeamento imagens do satélite Landsat 5-TM para 1985 e Landsat 8-OLI para 2015, disponibilizadas gratuitamente pelo USGS, priorizando períodos de baixas taxas pluviométricas. Após a aquisição das imagens em formato TIFF, foi criado um banco de dados no SPRING, no qual as imagens foram importadas para a

\begin{tabular}{lllll}
\hline Caminhos de Geografia & Uberlândia & v. 20, n. 72 & Dez/2019 & p. 560-573 Página 565
\end{tabular}


categoria imagem de modo com que cada cena ficasse alocada em um projeto diferente. Para cada projeto foi importado um arquivo vetorial no formato shapefile com a delimitação da área de estudo. Assim, cada uma das cenas foi recortada e áreas que extrapolavam o limite de análise foram eliminadas.

Posteriormente ao recorte, deu-se início ao processo de segmentação automática das imagens, utilizando área mínima, de acordo com o nível de detalhe que cada imagem exigia. Concluído o processo de segmentação as linhas foram exportadas da categoria imagem para a categoria temática.

Nessa categoria foram criadas as seguintes classes: agropecuária, herbáceo arbustivo, arbustoarbóreo, cicatriz erosiva, água, queimada, pivôs de irrigação, rocha, área urbana, mata ciliar ou várzea. Para a elaboração do mapa temático foi atribuído para cada uma das classes uma cor, e a classificação foi feita manualmente por meio do agrupamento de cada classe aos seus respectivos polígonos gerados na segmentação.

Para o mapeamento do ano de 2015 usou-se como auxílio a ferramenta do Google Earth para inspeção visual das classes de uso da terra, possibilitando maior aproximação e clareza dos objetos em análise. Para o ano de 1985 utilizou-se como referência as condições encontradas em 2015, além de um método dedutivo indireto e analítico.

Depois da classificação as cenas foram exportadas para o aplicativo ArcMap, onde foi efetuado o mosaico dos projetos que até então encontravam-se separados de acordo com o número da órbita ponto. Com isso, as informações quantitativas puderam ser analisadas como um todo, proporcionando a comparação entre as áreas e os anos, atribuindo para as mesmas o determinado "Factor CP" (Tabela 2), ou seja, um valor empírico entre 0 e 1 que indica o índice de proteção que determinada cobertura vegetal oferece ao solo, de modo que quanto menor a proteção ou maior a erodibilidade, mais próximo de 1.

Tabela 2 - Valor CP das classes de UCT.

\begin{tabular}{cc}
\hline Classe & CP \\
\hline Queimada & 1 \\
Cicatriz erosiva & 1 \\
Pivôs de irrigação & 0,09 \\
Agropecuária & 0,07 \\
Herbáceo-arbustivo & 0,05 \\
Arbusto-arbóreo & 0,01 \\
Mata ciliar/Várzea & 0,001 \\
Água & 0 \\
Área urbana & 0 \\
Rocha & 0
\end{tabular}

Fonte: Elaboração do autor. Ano: 2018.

\section{RESULTADOS E DISCUSSÕES}

A rápida e intensa mudança no UCT, sobretudo através da retirada da vegetação, ocasiona alterações nas propriedades físicas e químicas do solo, o que compromete sua fertilidade, condiciona a perda da produtividade e simultaneamente a perda da resistência à erosão (SILVA et al., 2007).

Para Silva et al. (2007), a distribuição do fenômeno da erosão sobre grandes áreas e as medidas de controle são fortemente estudados e visam determinar as relações existentes entre erosão, condições naturais e econômicas, além de avaliar a evolução dessas condições no tempo e no espaço. O 
avanço da tecnologia, principalmente aquela relacionada à informatização, permitiu novas abordagens para a análise de processos erosivos, utilizando modelos matemáticos como ferramentas de previsão, planejamento e controle.

Essas tecnologias e modelos matemáticos permitiram gerar uma estimativa de perda de solo para a área de estudo, levando-se em conta a classificação do UCT, tipo de solo, relevo e precipitação, fatores no qual o único que possui influência antrópica direta é o uso da terra. Para esse foram classificadas dez variáveis, conforme mostra o mapa de UCT (Figura 3) e, para cada uma delas, estabelecido um valor empírico que representasse seu grau de proteção, de modo que os maiores valores fossem associados às classes que apresentassem pouca ou nenhuma cobertura, como por exemplo, o solo exposto e as queimadas (Tabela 2).

Figura 3 - Mapa de classificação de Uso e Cobertura da Terra para a região do extremo Oeste baiano nos anos de 1985 e 2015.

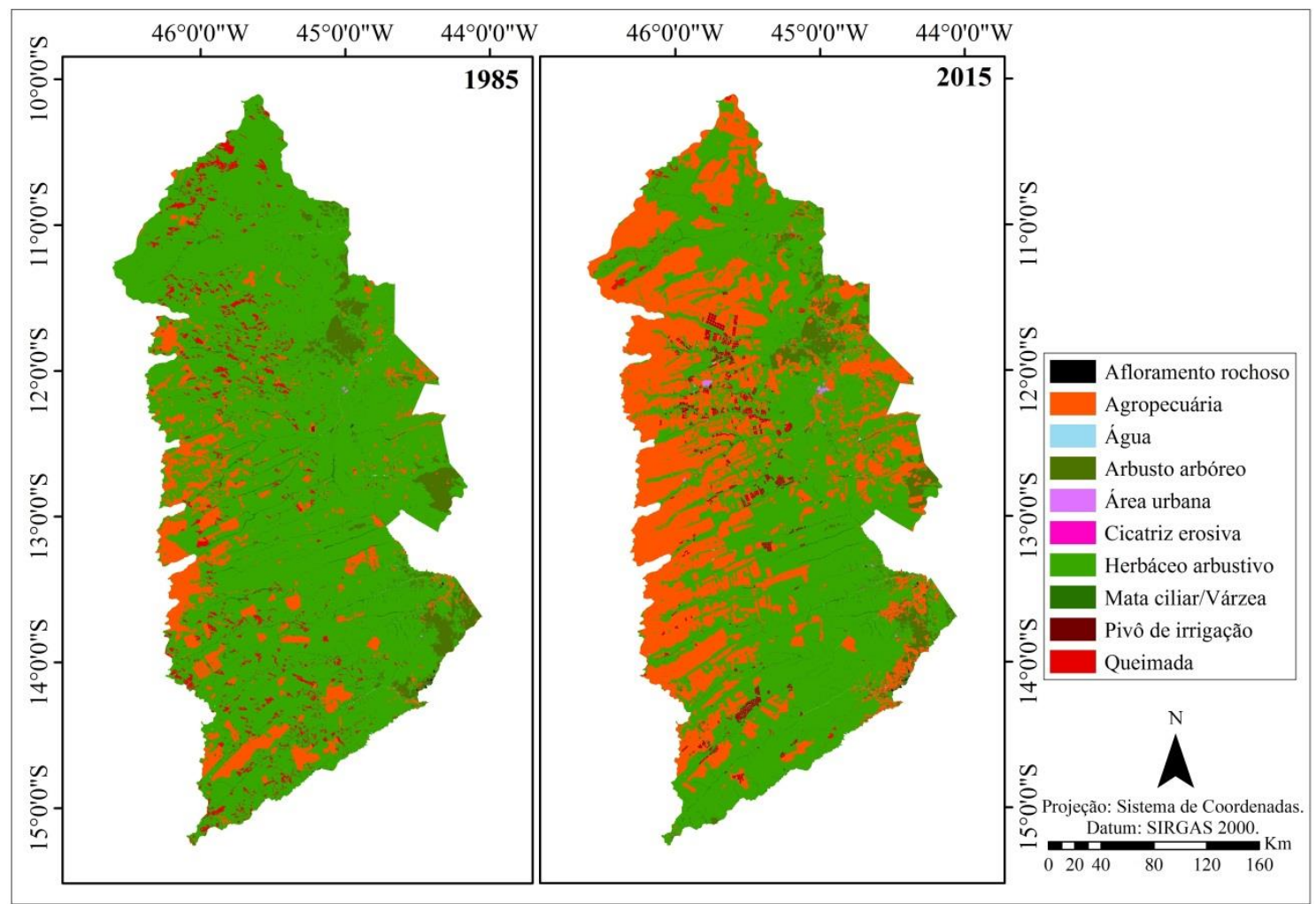

Fonte: Elaborado pelo autor. Ano: 2018.

Os resultados obtidos a partir da classificação do UCT possuem influência direta na EUPS e estão descriminados abaixo de modo a efetuar uma comparação entre as transformações ocorridas na região no decorrer de trinta anos (Tabela 3). As classes água, área urbana e afloramento rochoso foram desprezadas na análise por terem recebido valor zero no fator CP. 
Tabela 3 - Comparativo entre as áreas e classes nos anos de 1985 e 2015.

\begin{tabular}{ccc}
\hline CLASSE & $\mathbf{1 9 8 5}\left(\mathbf{e m ~} \mathbf{K m}^{2}\right)$ & $\mathbf{2 0 1 5}\left(\mathbf{e m ~} \mathbf{~ m}^{2}\right)$ \\
\hline Agropecuária & 8.585 & 31.519 \\
Arbusto arbóreo & $3.700,54$ & 3096,5 \\
Cicatriz erosiva & 3,12 & 17,93 \\
Herbáceo arbustivo & $72.085,8$ & $51.308,727$ \\
Mata ciliar/várzea & $1.150,96$ & 981,009 \\
Pivô de irrigação & 11,78 & 1278,0 \\
Queimada & 3.044 & 298,75 \\
\hline
\end{tabular}

Fonte: Elaborado pelo autor. Ano: 2018.

Diante dos dados observa-se uma representativa alteração na cobertura da terra entre os anos de 1975 e 2015, uma supressão sem precedentes da vegetação nativa em detrimento da expansão agrícola, o que acarreta danos irreversíveis ou de complexa resiliência ao meio ambiente.

Todavia, mesmo diante de números tão expressivos e consequências danosas, o processamento da EUPS apontou uma estimativa de que a perda de solo por erosão no ano de 1985 foi $29 \%$ superior a 2015 (Figura 4).

Figura 4 - Perda de solos por erosão para a região do extremo Oeste baiano nos anos de 1985 e 2015.

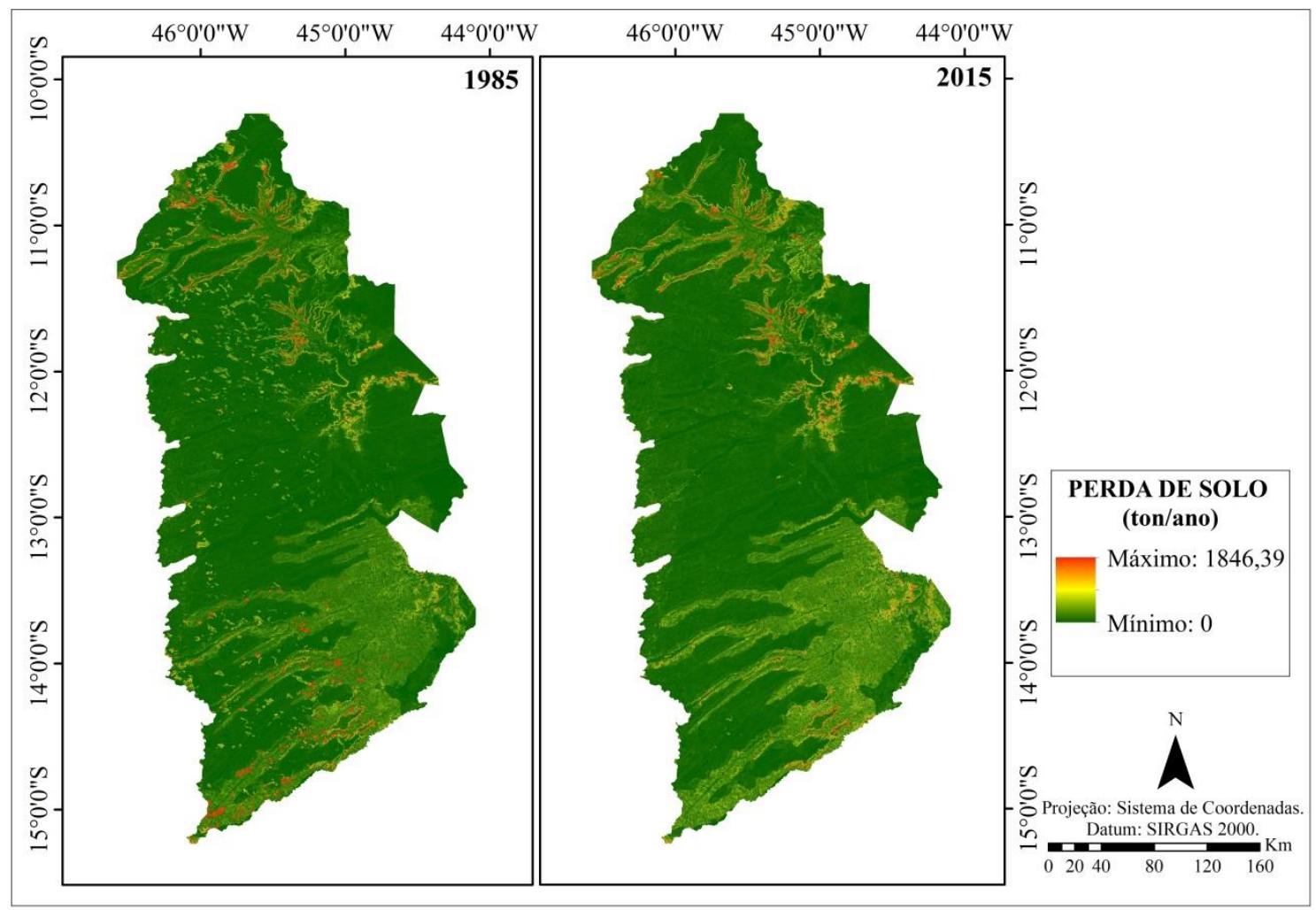

Fonte: Elaborado pelo autor. Ano: 2018.

As altas taxas obtidas na análise referente a 1985 provêm da grande quantidade de áreas queimadas nesse período. Essa década indicava o auge da expansão e conversão da vegetação nativa em áreas de cultivo, e o fogo era o principal método para efetuar o processo, deixando, mesmo que temporariamente, grandes parcelas de solo desnudado, o que proporcionou aumento das taxas de

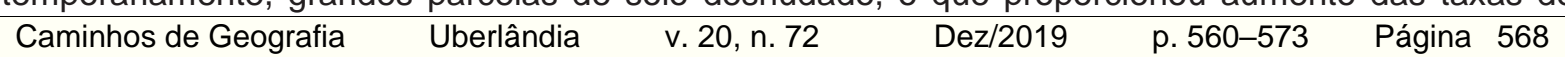


erosão. Segundo Pereira e Vieira (2001) pode-se pressupor que o plantio mecanizado de grãos contribui na redução de uso do fogo para o preparo de área. Pedroso Júnior et al. (2008) cita que em Lampung, na Indonésia, até 1930 a agricultura de corte e queima era dominante, onde houve uma substituição gradual por uma agricultura mais intensiva, até que, no início da década de1970, não havia mais áreas florestadas e as queimadas deixaram de ser praticadas.

No oeste baiano, apesar do processo de expansão se manter crescente, assim como as taxas de desmatamento, 2015 também já não era o pico de conversão, considerando que grande parte das terras agricultáveis, sobretudo no leste da área de estudo, já haviam sido convertidas e cultivadas, não se utilizando do fogo com a mesma frequência e oferecendo maior proteção ao solo do que quando desprovido de cobertura vegetal.

A análise apontou também que nos locais onde as declividades são superiores a $20 \%$ as perdas de solo se intensificam, aumentando de maneira proporcional ao aumento da declividade. A observação fica evidente ao se comparar os mapas de perda de solo (Figura 4) com o mapa de declividade (Figura 5).

Figura 5 - Mapa de declividade para a região do extremo Oeste baiano no ano de 2015

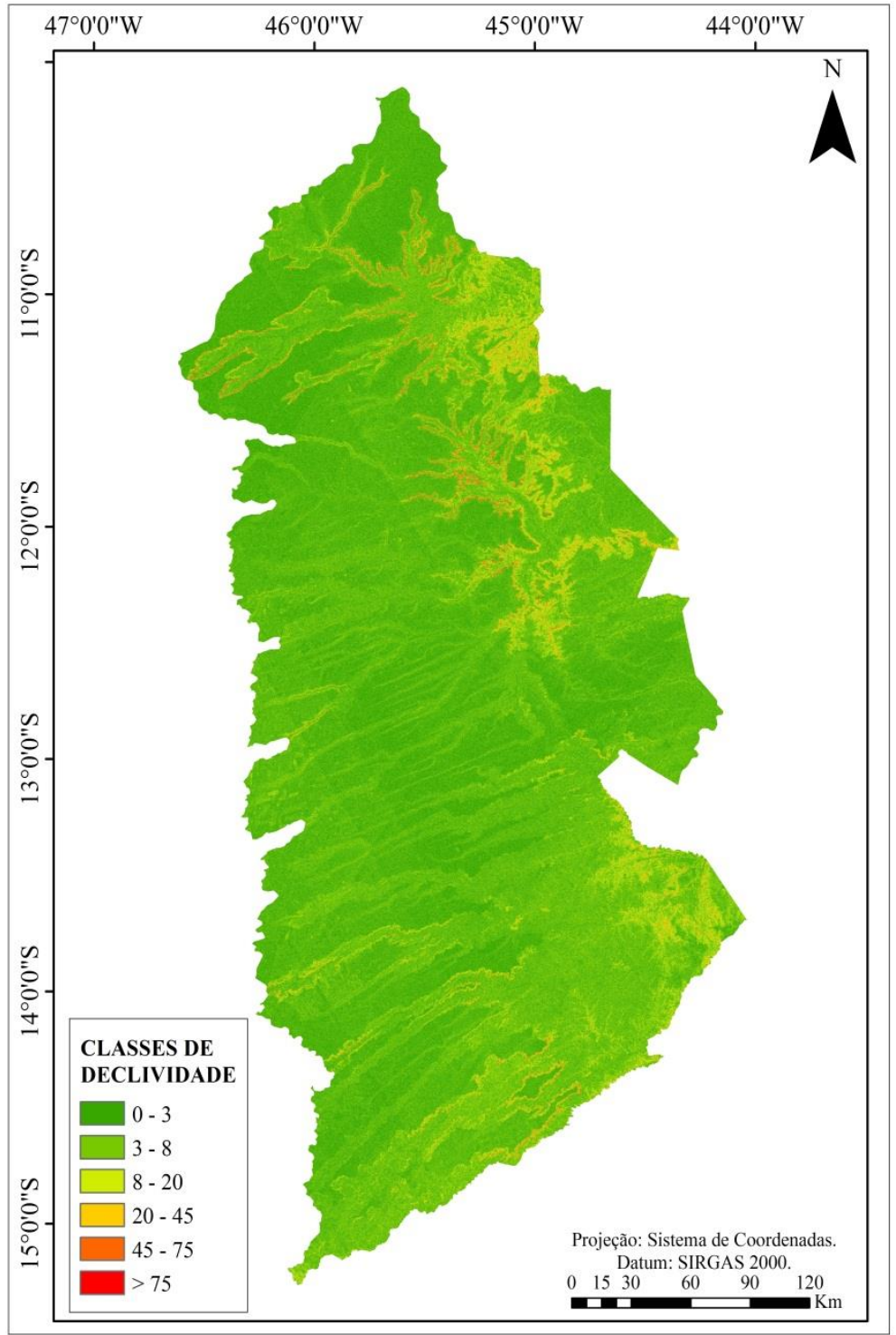

Fonte: Elaborado pelo autor. Ano: 2018. 
Pode-se considerar que, apesar do processo erosivo natural nessas áreas ser mais acelerado, a retirada da vegetação contribui para esse aumento, já que a ausência da mesma favorece o fluxo difuso da precipitação e consequentemente um maior arraste de partículas. Além disso, Segundo Troeh e Thompson (2007) a topografia modifica o microclima e a vegetação, produzindo efeito na quantidade de matéria orgânica e marcante movimento de água e solo. Os solos de áreas declivosas apresentam maior escoamento superficial, o que gera menor disponibilidade de água para as plantas e, consequentemente, crescimento vegetal deficiente.

Outro fato a ser observado é que as maiores perdas de solo ocorrem nas áreas em que há predominância de Neossolos Litólicos e Quartizarênicos (Figura 6). Esses solos são pouco desenvolvidos, não hidromórficos e de textura normalmente arenosa, apresentando alta erodibilidade principalmente em declives mais acentuados (EMBRAPA, 2013), além de conterem baixos teores de carbono orgânico total, fósforo e baixa capacidade de troca catiônica (SANTOS et al., 2012). Troeh e Thompson (2007) acreditam que nesses solos ocorre dificuldade na fixação da vegetação, pois são arenosos, mornos e bem arejados, o que favorece rápida decomposição e não acúmulo de matéria orgânica, menor retenção de água e menor fertilidade. Isso confere menor crescimento de plantas do que nos solos argilosos, que tendem a estabilizar os componentes orgânicos contra a decomposição.

Figura 6 - Mapa de solos da região do extremo Oeste baiano.

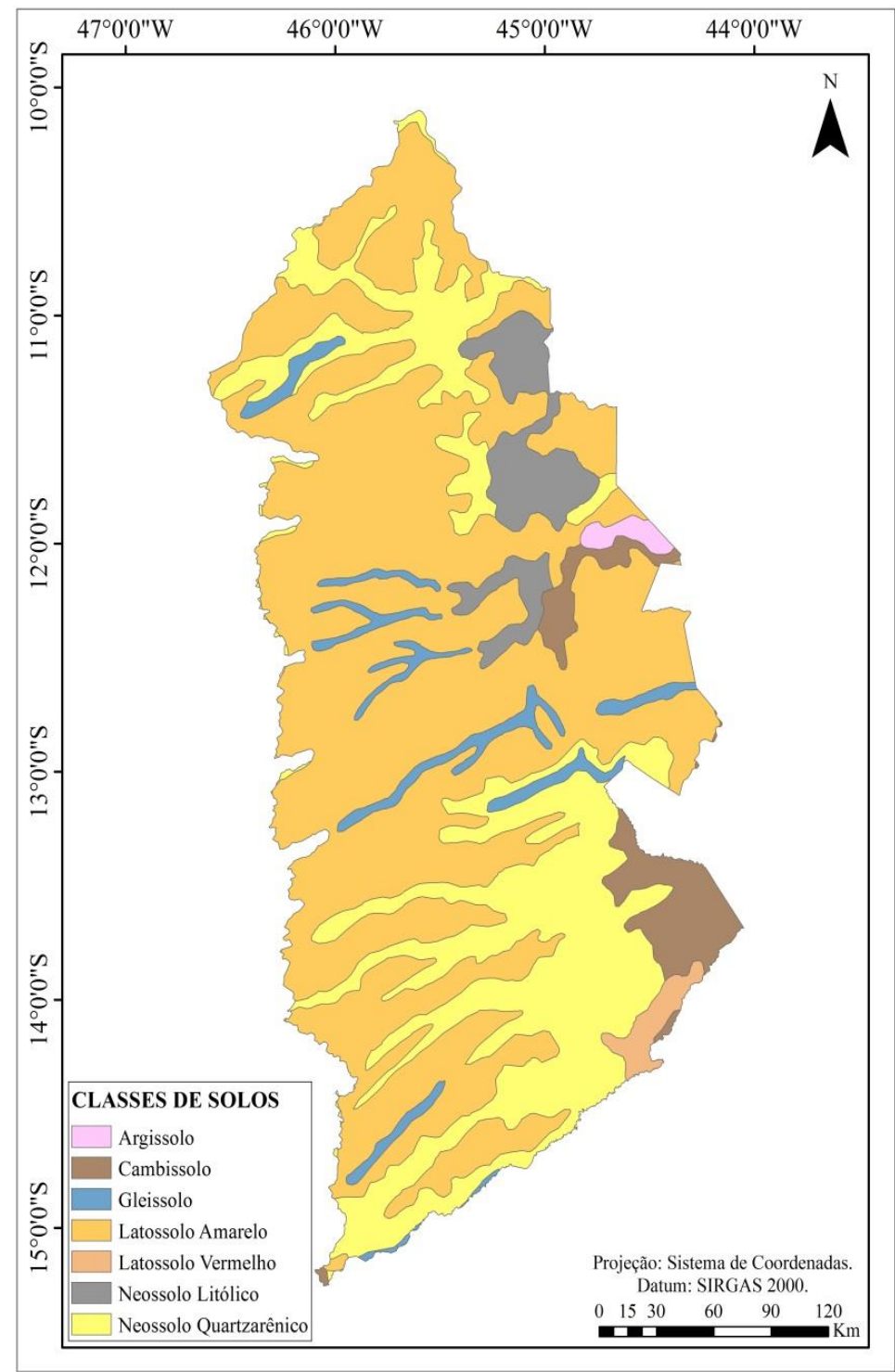

Fonte: Elaborado pelo autor. Ano: 2018. 
Para Chistofoletti (1980) as areias, principalmente as finas, são as partículas mais susceptíveis ao transporte pelo efeito splash. Guerra et al. (2010) apontam que pesquisas efetuadas na Inglaterra concluíram que a erosão em solos arenosos ocorre de forma generalizada pelas encostas e em volume maior que em solos argilosos, onde os processos erosivos ocorrem principalmente nos fundos de vale.

\section{CONSIDERAÇÕES FINAIS}

Apesar da grande supressão da vegetação, fator que intensifica os processos erosivos, a análise das perdas de solo utilizando a EUPS indica que o ano de 1985 apresenta valores 29\% maiores que em 2015. A explicação para o fato é dada considerando que as áreas de vegetação nativa estavam sendo convertidas em áreas agrícolas por meio das queimadas, o que deixava o solo temporariamente exposto.

Ressalta-se que o resultado não deve ser avaliado sem os devidos critérios, pois aparentemente pode advertir que 0 avanço das culturas agrícolas sobre a vegetação nativa exerce mais proteção ao solo, o que não é verdade. O fato é que o intervalo de tempo estudado, trinta anos, corresponde a dois extremos do histórico "desenvolvimentista" do cenário agrícola brasileiro. Na década de 1980, a grande disponibilidade de terras e o projeto de transformar o Brasil em "Celeiro Mundial" fazia com que a expansão das culturas agrícolas ocorresse em uma velocidade maior e com técnicas rudimentares de supressão da vegetação nativa, como o fogo.

A utilização dessa técnica agride o solo e o deixa temporariamente exposto às intempéries, o que favorece a aceleração dos processos erosivos. Desse modo, na classificação de vulnerabilidade das classes que compuseram o fator CP da EUPS, a classe "queimada" recebeu o valor 1, ou seja, baixa proteção ao solo, e como no ano de 1985 o número de queimadas classificadas foi altamente significativo, acentuou-se a frequência de solos expostos.

Para a suposta redução da perda se solo no ano de 2015 dois fatores podem ser apontados. Primeiro, pode-se mencionar as leis que controlam a utilização do fogo como forma de "limpeza" do cultivo, o que consequentemente impede a exposição total solo. Em segundo lugar, as áreas que foram consideradas como de alta vulnerabilidade à perda de solos em 1985, devido às queimadas, encontram-se em sua maioria cultivadas em 2015, o que oferece uma pequena proteção a mais do que se estivessem expostas como estavam logo após a abertura do front.

Os resultados finais indicam a necessidade de se realizar novos mapeamentos de UCT, sobretudo nos períodos pós anos 2000, uma vez que a maior conversão para áreas agrícolas diminui o emprego do fogo.

\section{AGRADECIMENTOS}

À Coordenação de Aperfeiçoamento de Pessoal de Nível Superior (CAPES) pelo apoio à pesquisa e concessão de bolsa de estudos.

\section{REFERENCIAS BIBLIOGRÁFICAS}

BATISTELLA, M; GUIMARÃES, M; MIRANDA, E.E, et al. Monitoramento da Expansão Agropecuária na Região Oeste da Bahia. EMBRAPA Monitoramento por satélite; 39p, 2002.

BERTONI, J; LOMBARDI NETO, F. Conservação do Solo. 5 ed. São Paulo: Ícone, 2008.

BORGES, K.M.R. Avaliação da susceptibilidade erosiva da Bacia do Rio Carinhanha (MG/BA) por meio da EUPS - Equação Universal de Perda de Solos. 2009. 80f. Dissertação (Mestrado em Gestão ambiental e territorial) - Programa de Pós-Graduação em Geografia, Universidade de Brasília. Brasília, 2009a.

\begin{tabular}{llllll}
\hline Caminhos de Geografia & Uberlândia & v. 20, n. 72 & Dez/2019 & p. 560-573 Página 571
\end{tabular}


CARVALHO JUNIOR, O.A; CARVALHO, A.P.F; RODRIGUES, N.Q; GUIMARÃES, R.F. Confecção do Mapa de Susceptibilidade à Erosão a Partir da EUPS Utilizando para estimar of ator topográfico o programa rampa. In: VII Simpósio Nacional de Controle de Erosão, 2001, Goiânia. Anais [...] Goiânia, Goiás: Universidade Federal de Goiás. 2001, p. 26-40. Disponível em: https://www.labogef.iesa.ufg.br/links/simposio_erosao/articles/T027.pdf. Acessado em 15 ago. 2015.

CHAVES, H.ML. Estimativa da erosão atual e potencial no vale do São Francisco: Relatório final de consultoria. Brasília: CODEVASF. 35 p, 1996.

CHRISTOFOLETTI, A. Geomorfologia. 2. ed. São Paulo: Editora Edigard Blücher Ltda, 1980. 188 p.

FUJACO, M.A.G. O uso do sensoriamento remoto e da cartografia digital na gestão de bacias hidrográficas agrícolas. 2017. 127 f. Tese (Doutorado em Evolução Crustal e Recursos Naturais) Escola de Minas, Universidade Federal de Ouro Preto. Ouro Preto, 2017. https://doi.org/10.1590/0370-44672015690197

FUJACO, M.A.G; LEITE, M.G.P; NEVES, A.H.C.J.A gis-based tool for estimating soil loss in agricultural river basins. Rem - International Engineering Journal, [s.I.], v. 69, n. 4, p.417-424, dez. 2016.

GUERRA, A.J.T; SILVA, A.S; BOTELHO, R.G.M (Org.). Erosão e Conservação dos Solos Conceitos, temas e aplicações. 6. ed. Rio de Janeiro: Bertrand Brasil, 339p. 2010.

HONGFEN, E.N.G et al. Improving Rainfall Erosivity Estimates Using Merged TRMM and Gauge Data. Remote Sensing, [s.l.], v. 9, n. 12, p.1134-1149, 6 nov. 2017. https://doi.org/10.3390/rs9111134

LAFLEN, J.M.; FLANAGAN, D.C.The development of U. S. soil erosion prediction and modeling. International Soil And Water Conservation Research, [s.I.], v. 1, n. 2, p.1-11, set. 2013. https://doi.org/10.1016/S2095-6339(15)30034-4

MINISTÉRIO DO MEIO AMBIENTE (MMA). Download de dados geográficos. Disponível em: http://mapas.mma.gov.br/i3geo/datadownload.htm. Acesso em: jun/2017.

OLIVARES, B; LOBO, D; VERBIST, K. Aplicación del modelo USLE en parcelas de erosión bajo prácticas de conservación de suelos y aguas en San Pedro de Melipilla, Chile. Revista Ciencia e Ingeniería, Universidad de Los Andes, v. 36, n. 1, p.03-10, jan. 2015. Disponível em: <http://erevistas.saber.ula.ve/index.php/cienciaeingenieria/article/view/5490 >. Acesso em: Abr/2016

PATIL, R; SHARMA, S.K; TIGNATH, S. Remote Sensing and GIS based soil erosion assessment from an agricultural watershed. Arabian Journal Of Geosciences, [s.I.], v. 8, n. 9, p.6967-6984, 27 nov. 2014. Springer Science + Business Media. Acesso em: Abr/2016. https://doi.org/10.1007/s12517-014$\underline{1718-y}$

PEDROSO JÚNIOR, N.N; MURRIETA, R.S.S; ADAMS, C. A agricultura de corte e queima: um sistema em transformação. Boletim do Museu Paraense Emílio Goeldi, São Paulo, v. 3, n. 2, p.153174, 2008. https://doi.org/10.1590/S1981-81222008000200003

PEREIRA, C.A; VIEIRA, I.C.G. A importância das florestas secundárias e os impactos de sua substituição por plantios mecanizados de grãos na Amazônia. Interciência, Caracas, v. 26, p.337341, ago. 2001.

PINHEIRO, L.S. A dinâmica erosiva na Bacia do Córrego Ibitinga - Rio Claro (SP): uma abordagem empírico-dedutiva. 2012. 139 f. Tese (Doutorado em Organização do Espaço) Programa de Pós-Graduação em Geografia, Instituto de Geociências e Ciências Exatas., Universidade Estadual Paulista "Júlio de Mesquita Filho", Rio Claro - SP, 2012.

PRUSKI, F.F. Conservação de solo e água: Práticas mecânicas para o controle da erosão hídrica. Viçosa: Ed. Viçosa, 2010.

QUEIROZ, B.G. A mudança de centralidade urbana no oeste da Bahia: o caso de Luis Eduardo Magalhães e Barreiras (BA). 2012. 42 f. Trabalho de Conclusão de Curso (Bacharelado em Geografia) - Faculdade de Geografia, Universidade Estadual de Campinas, Campinas, 2012. 
SILVA, A.M; SCHLZ, H.E; CAMARGO, P.B. Erosão e hidrossedimentação em bacias hidrográficas. 2. ed. São Carlos: Rima Editora, 2007. 153 p.

TROEH, F. R.; THOMPSON, L. M. Solos e Fertilidade do Solo. São Paulo: Andrei, 2007. 718p.

UDDIN, K; MURTHY, M.S.R; WAHID, S; MATIN, M. Estimation of Soil Erosion Dynamics in the Koshi Basin Using GIS and Remote Sensing to Assess Priority Areas for Conservation. Plos One, [s.I.], v. 11, n. 3, p.1-10, 10 mar. 2016. Public Library of Science (PLoS). Disponível em:

http://journals.plos.org/plosone/article?id=10.1371/journal.pone.0150494. Acesso em: Abr/2016. https://doi.org/10.1371/journal.pone.0150494

WISCHMEIER, W.H; SMITH, D.D. Agricultural Research Service U.S (Org.). Predicting Rainfall Erosion Losses From Cropland East of the Rocky Mountains. In: Agriculture Handbook 282:

Departament Of Agriculture United States, Washington, 1965. 47p.

Recebido em: 07/11/2018

Aceito para publicação em: 03/09/2019 